Research article

\title{
Colonization of stem borer damaged maize plants by aflatoxigenic Aspergillus species in Zimbabwe
}

\author{
N. Nleya*, Y. O. Nyararai, M. Mawanza and F. N. Mlalazi \\ National University of Science and Technology, Department of Applied Biology and Biochemistry, Box AC \\ 939, Ascot, Bulawayo, Zimbabwe
}

*Corresponding Author: ndangwa@gmail.com

[Accepted: 05 March 2017]

\begin{abstract}
The worldwide contamination of food and feed with mycotoxins is a significant problem. Aflatoxins are major mycotoxins of agro-economic importance produced by some Aspergillus species. Aflatoxigenic Aspergillus species were isolated from insect larvae damaged maize stalks and characterized. The fungi were isolated from the stems, ears and silks of the plant. Aflatoxin production by the isolates was determined using the ammonium hydroxide method as well as the ultra violet fluorescence method. The Lepidopteran species feeding on the crop was identified as Busseola fusca. The Aspergillus species isolated were identified as Aspergillus flavus and Aspergillus parasiticus. This was done using macro- and microscopic features. A total of 35 isolates were obtained of which only 17 were aflatoxigenic. From the aflatoxigenic species $88 \%$ were A. parasiticus whilst $12 \%$ were A. flavus. Insects were however negative for aflatoxigenic fungi implying that these insects do not act as direct vectors of aflatoxigenic fungi, but however predispose the crop to fungal infection by damaging the physical barrier.
\end{abstract}

Keywords: Aflatoxins - Busseola fusca - Stalk borer - Vectors.

[Cite as: Nleya N, Nyararai YO, Mawanza M \& Mlalazi FN (2017) Colonization of stem borer damaged maize plants by aflatoxigenic Aspergillus species in Zimbabwe. Tropical Plant Research 4(1): 109-114]

\section{INTRODUCTION}

Corn (Zea mays) is the most important cereal crop in the world after wheat and rice and belongs to the grass family Gramineae (Karthikeyan et al. 2013). Cereal grains and their products are the main foods for human consumption throughout the world. In Zimbabwe maize is of great importance as it the primary staple food and occupies about half of the agricultural land (Sithole 1989). It is consumed in a wide variety of ways. Green maize fresh on the cob is eaten roasted or boiled; grain is used in traditional dishes (such as umxhanxa and inkobe) or ground to mealie-meal to make porridge and paste (sadza/ isitshwala). Maize is also an important livestock feed both as silage and as crop residue.

The maize grain is vulnerable to contamination by mycotoxigenic fungi if damaged by insect pests. These moulds include Aspergillus, Penicillium and Fusarium species. Aflatoxins are a group of mycotoxins produced by some Aspergillus species namely, A. flavus, A. parasiticus and rarely A. nomius (Dvorackova 2000). These moulds are able to colonize a wide range of crops both in the field as non-destructive pathogens and in storage. Damage from insects feeding provides preferential sites for penetration by fungi, with some insects acting as vectors of fungi (Samapundo 2006). The main insects implicated in maize production is the maize stem borer complex which comprise of the maize stalk borer; Busseola fusca, the pink stalkborer; Sesamia calamistis, the spotted stem borer; Chilo partellus and the sugarcane stem borer; Eldana saccharina (Capinera 2008). Stem borer infestations range from $30-70 \%$ in fields of poor resourced farmers and less than $30 \%$ in commercial farms where insecticides are used for control (Sithole 1989).

Insect larvae that feed on developing corn kernels are implicated in the establishment of Aspergilli infection and subsequent contamination of the seed with aflatoxins before harvest. These insects facilitate the entrance of Aspergilli from outside the plant into the ears of the crop (Lawley et al. 2012). Insects infect kernels through the following ways; (i) they transport primary inoculum to the ears, (ii) they move inoculum from the silks into the ear, (iii) they disseminate inoculum within the ear and (iv) they wound intact tissue providing more infection 
sites. Wounding may also allow kernels to dry down to moisture levels that support the growth of Aspergillus and subsequent aflatoxin production (Giorni 2007, Samapundo 2006).

Aflatoxins are one of the major etiological factors in the development of hepatocellular carcinoma (IARC 2002). There are four naturally occurring aflatoxins aflatoxin (AF) $B_{1}, B_{2}, G_{1}$ and $G_{2}$. Mammals that ingest $\mathrm{AFB}_{1}$ and $\mathrm{AFB}_{2}$ contaminated diets eliminate into milk amounts of the principal 4-hydroxylated metabolite known as "milk toxin" or $\mathrm{AFM}_{1}$ and $\mathrm{AFM}_{2}$. These hydroxylated metabolites are potential contaminants in dairy foods. As such, aflatoxins are not only of importance in humans alone but in animals as well (Samapundo 2006). This results in corn, when consumed as a staple food, being a major dietary source of mycotoxins to both public and animal health (Samapundo 2006). The aim of the study was to isolate and characterize aflatoxigenic Aspergillus that are associated with insect larvae damaged maize stalks in order to assess the impact of damage to aflatoxin contamination in maize.

\section{METHODS AND MATERIALS}

\section{Sampling}

A total of 20 maize plants damaged by the maize stalk borer were obtained from a small scale field in Manningdale, Bulawayo in Zimbabwe. The maize plants were taken to the laboratory where they were sundried to reduce the moisture content. Nodes of the stem showing insect damage were cut and the surface swabbed using $70 \%$ ethanol. Using a sterile blade, each node was cut vertically so as to expose the damaged tissue.

Corn ears showing insect damage were removed from the stalk, and the leaves were removed to expose the damaged tissue. Scrapings of the damaged grain were aseptically placed on malt extract agar and the plates incubated at $25^{\circ} \mathrm{C}$ for 5 days. From each of the 20 ears, $2 \mathrm{~mm}$ portions of the silks were excised and placed on MEA and incubated at $25^{\circ} \mathrm{C}$ for 5 days.

The insect larvae that were found feeding on the stems and ears were surface sterilized using $2 \%$ sodium hypochlorite, followed by two washes in sterile water. This was done so as to remove any microorganism on the surface of the insect, and to allow isolation of fungi present within the insect. Each insect was then placed on MEA, and the plates incubated at $25^{\circ} \mathrm{C}$ for 5 days. Insect pupae obtained from both stems and ears were placed in jars, where they were allowed to complete their life cycles so as to enable easy identification of the species.
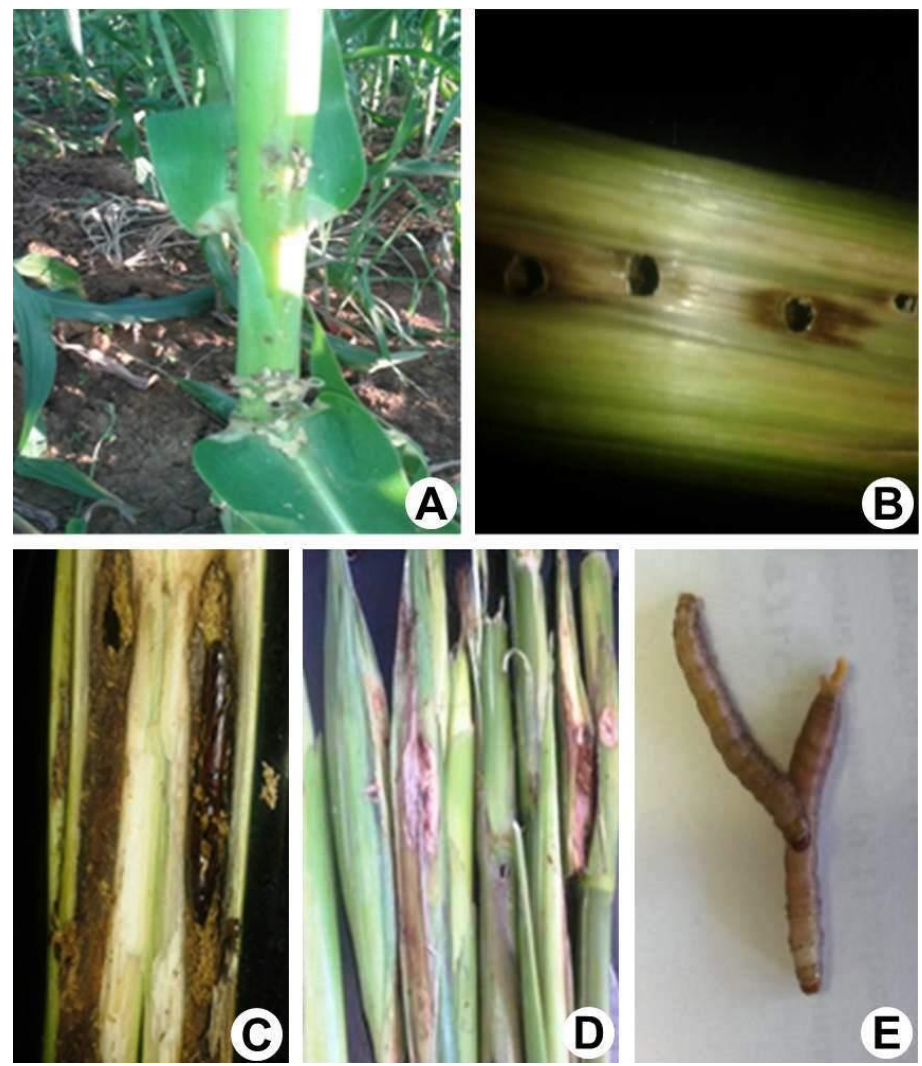

Figure 1. A, Maize plant showing signs of stalk borer attack; B, Maize stalk showing points through which the stalk borer penetrated the plant; C, Pupae of the stalk borer inside the maize stalk; D, Ears showing damage by the stalk borer; E, Busseola fusca larvae isolated from maize plants. 


\section{Identification of isolates}

Identification of the fungal isolates was done using colony morphology and microscopy. Microscopy was done using Motic digital microscope and the captured images were identified by comparing images from (Baquaiao et al. 2013, Ellis et al. 2007, Watanabe 2002).

\section{Detection of aflatoxins}

The isolates' ability to produce aflatoxins was carried out using the ammonium hydroxide method by Saito \& Machida (1999) after growing the isolates on yeast extract sucrose (YES) agar. To determine the type of aflatoxin produced by positive isolates from the ammonium hydroxide test, the UV fluorescence determination according to Davies et al. (1987) using coconut agar media was carried out.

\section{RESULTS}

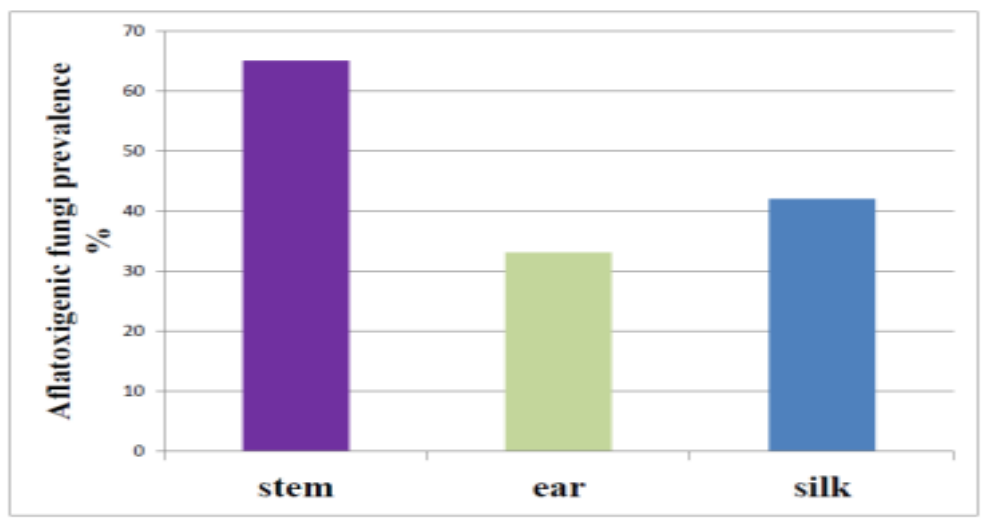

Figure 2. The distribution of Aspergillus in the maize plants.

The insects that were isolated from the maize stalks belonged to one species i.e. Busseola fusca as shown in figure 1. From the 20 maize plants that were sampled Aspergillus was isolated from 12 maize plants. Figure 2 shows the distribution of Aspergillus species in maize plants. Aspergillus was isolated from $63 \%$ of the plants sampled whereas no Aspergillus was present in the remaining $37 \%$.

Table 1. Macroscopic features used to identify the Aspergillus isolates.

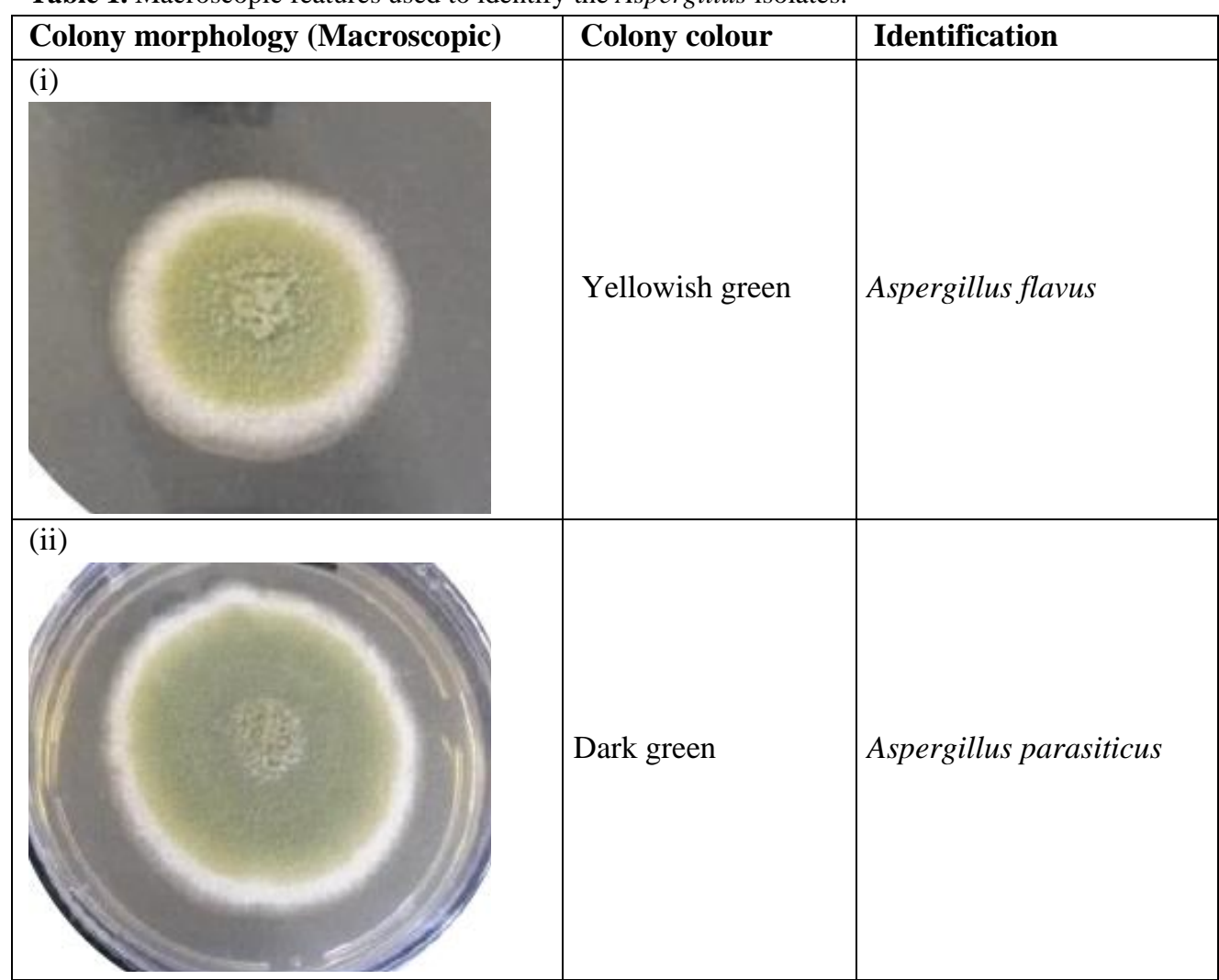


Table 2. Microscopic features used in the identification of Aspergillus isolates.

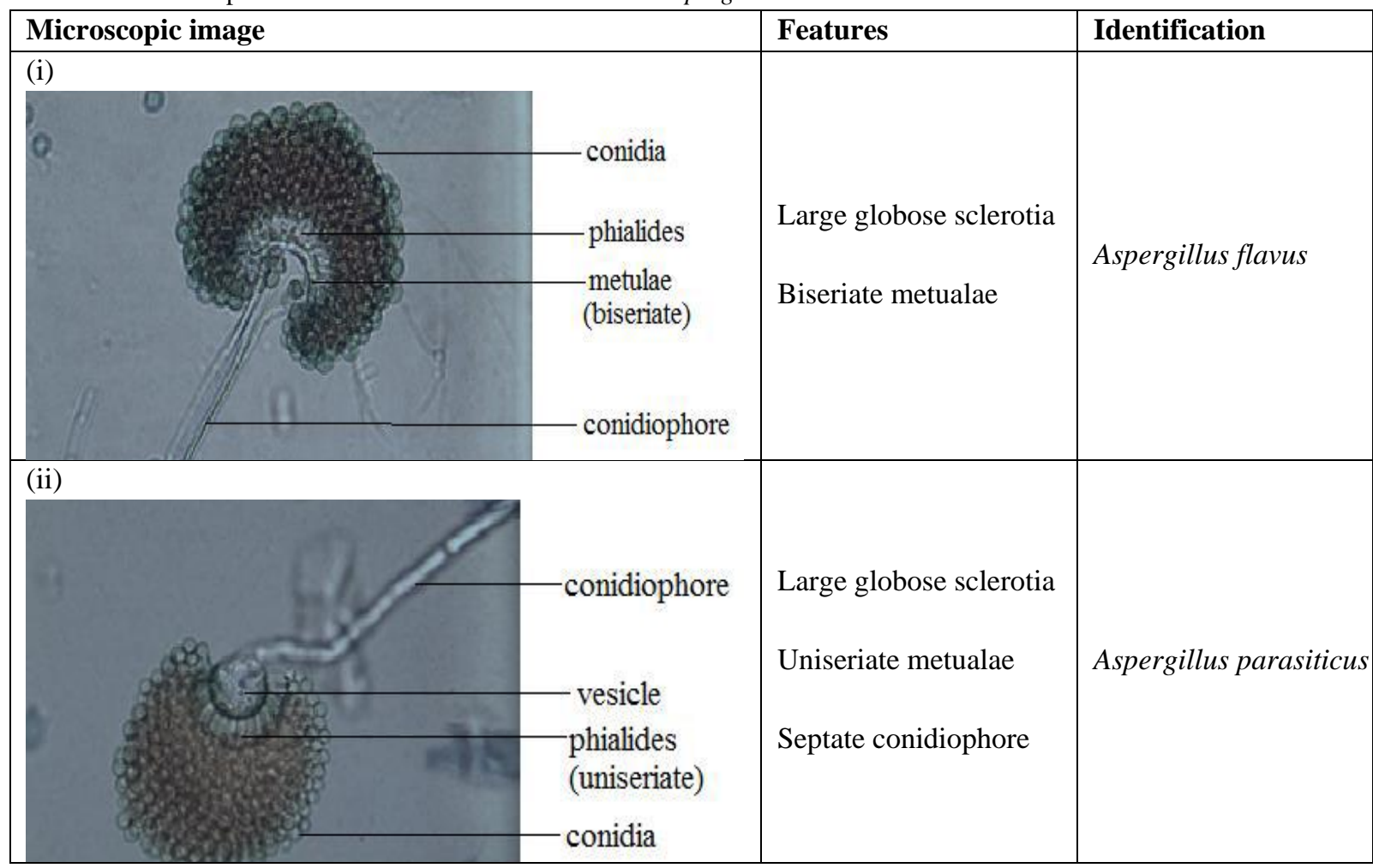

A total of 35 isolates was obtained. Isolates were obtained from the ears, silks and stems. No Aspergillus was isolated from the insects. The 35 isolates belonged to two species namely Aspergillus flavus and Aspergillus parasiticus. The predominating species was A. parasiticus. Macroscopic and microscopic features were used in the identification of the species as shown in table 1 and 2 respectively. The isolates' ability to produce aflatoxins was done using the ammonium hydroxide test were aflatoxin producers were identified by a change in colour as shown in figure 3.

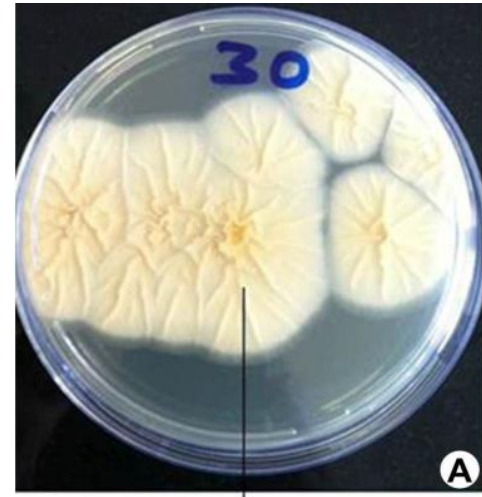

isolate before ammonium hydroxide test

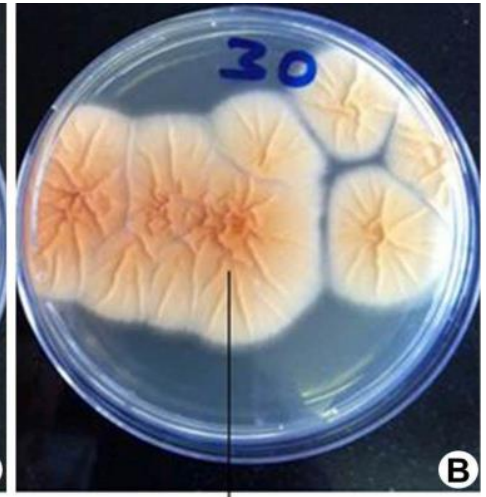

isolate after ammonium hydroxide test

Figure 3. Photograph of an aflatoxigenic isolate before (A) and after $(\mathbf{B})$ screening. Before screening the underside of the plate was cream in colour, and after screening the plate had developed an orange-pinkish colour due to reaction of aflatoxin biosynthetic intermediates and ammonium hydroxide.

\section{DISCUSSION}

Stalk tunnelling was evident in all the maize plants that had been attacked by the stalk borer (Fig. 1C) due to the feeding of the insect larvae feeding on the plant stem tissue. The insect species was identified as Busseola fusca (Fig. 1D) which is also known as the African maize stalk borer or the Fuller, and it is the most common maize pest in Zimbabwe and Sub-Saharan Africa (Sithole 1989). The tunnelling action of B. fusca predisposes the plant to penetration by fungi, some of which are aflatoxigenic (Samapundo 2006). Members of the Aspergillus species section Flavi where isolated from the tunnel scrapings and these were A. flavus and A parasiticus. These were identified by their characteristic conidial heads which occur in shades of yellow-green 
to brown (Gupta 2012) as shown in table 1. Aspergillus species were isolated from $63 \%$ of the maize plants. $A$. parasiticus and A. flavus are the major aflatoxigenic species in the world (Samapundo 2006). Both species produce the most potent aflatoxin, AFB1. This ability to produce AFB1 in maize makes them a significant threat to both humans and livestock who may consume this contaminated maize and maize stalks respectively. In addition to AFB1, A. flavus and A. parasiticus produce AFB2. Together AFB1 and AFB2 when consumed by mammals are metabolically biotransformed to AFM1 and AFM2 and are excreted in milk. This has a negative impact on nursing animals which may suffer from aflatoxicosis (Gupta 2012). Also, in the commercial set up, contamination of feed with A. flavus and A. parasiticus may result in contamination of the milk designated for consumer use. If regulatory laws are thorough, such milk may not be released for consumer use, thus entailing economic losses to dairies.

In order to determine the role of insects as vectors of fungi, insect larvae were surface sterilized and cultured on MEA. No aflatoxigenic fungi or Aspergillus species was isolated from them. This means that insects may not directly act as hosts of fungi. The stalk borer breaks open the physical barrier allowing the fungi to access the plant tissue. According to Giorni (2007) wounding of the kernels and stems by insects also reduces the moisture content and this favours the proliferation of A. flavus with subsequent aflatoxin production.

It was observed that the stems were damaged at several sites per stem node as compared to the damage per ear (Figs. 1B \&1D). This trend is greatly explained by the lifecycle of $B$ fusca on maize plants. The female $B$. fusca moth oviposit its eggs behind the vertical edges of leaf sheaths. After hatching the first instars migrate to the whorl where they feed on young and tender leaves deep inside the whorl. From the third instar onwards, larvae migrate to the lower parts of the plant where they penetrate into the stem. These larvae begin to feed on the stem, going up the plant to the ear. Thus the ear is usually infested by the pests at much later stages (Calatayad et al. 2014, Frérot et al. 2006). Results show that the stems had the highest prevalence of aflatoxigenic fungi of $65 \%$, followed by the silks (42\%) and the ears had the least prevalence of $33 \%$ (Fig. 2). The observed trend can be explained by the nutritional content, moisture content and environmental differences between these plant tissues. Stems have a high nutritional content packed with sugars and complex carbohydrates (Plessis 2003). This is favourable for both insect and fungal growth. Thus most fungi were able to proliferate within the stems as compared to the ears and silks. The silks had a moderate aflatoxigenic fungi prevalence of $42 \%$. Silks are exposed to the atmosphere as such these toxigenic fungi isolated may not be a result of insect activity, but a result of aflatoxigenic fungal spores flying in the atmosphere which adhere to silk surfaces.

In Zimbabwe, maize is the staple food consumed by the vast majority of the population. In the rural areas, households grow the crop themselves and use it to make the mealie-meal, which is consumed on a daily basis all year round. These communities often do not make use of pesticides due to financial constraints. As a result, damage of the crop by insects such as B. fusca as demonstrated in the study, allows growth of A. flavus and A. parasiticus. This means that these communities are at a risk of aflatoxin poisoning. Furthermore, crop residues that remain after a season's harvest are given to cattle as feed during the dry season exposing the livestock to aflatoxin poisoning as the dry stalks and cobs offer the desirable conditions for Aspergillus proliferation, as demonstrated in the study. Therefore there is a need to develop strategies of controlling or eliminate stem borers in the communal areas such as cultural control. Cultural control is an economical method of stem borer control and has been adopted in West Africa. It includes methods such as removal and destruction of crop residues, intercropping, crop rotation and manipulation of planting dates (Ogah \& Ogbodo 2012). Biological methods can also be used to control the maize stalk borer for example the exchange of species and strains of natural enemies between regions, and the use of non-co-evolved natural enemies, as well as habitat management solutions, namely the use of trap plants such as wild grasses on which larval mortality can be very high (Cherry et al. 1999).

\section{ACKNOWLEDGEMENTS}

The authors would like to thank the support provided by the National University of Science and Technology and the Technical staff of the Department of Applied Biology and Biochemistry for their support.

\section{REFERENCES}

Baquaiao AC, de Oliveira MMM, Reis TA, Zorzete P, Atayde DD \& Correa B (2013) Polyphasic Approach to the identification of Aspergillus section Flavi isolated from Brazil nuts. Food Chemistry Journal 139: 1127-1132. 
Calatayad PA, LeRu BP, van den Berg J \& Schulthess F (2014) Ecology of the African Maize Stalk Borer, Busseola fusca (Lepidoptera: Noctuidae) with Special Reference to Insect-Plant Interactions. Insects 5(3) 539-563.

Capinera JL (2008) Encyclopedia of Entomology. Springer, USA, pp. 270-273.

Cherry AJ, Lomer CJ, Djegui D \& Schulthess (1999) Pathogen incidence and their potential as microbial control agents in IPM of maize stem borers in West Africa. BioControl 44: 301-327.

Davies ND, Iyer SK \& Diener UL (1987) Improved method of screening for aflatoxin with a coconut agar medium. Applid Environmental Microbiology 53: 1593.

Dvorackova I (2000) Aflatoxins and human health, CRC Press. USA, pp. 3-10.

Ellis D, Davis S, Alexiou H, Handke R \& Bartley R (2007) Descriptions of Medical fungi, $2^{\text {nd }}$ Edition. School of Molecular and Biomedical Science, University of Adelaide, Australia.

Frérot B, Félix AE, Sarapuu E, Calatayud PA, LeRü B \& Guenego H (2006) Courtship behaviour of the African Maize Stem Borer: Busseola fusca (Fuller) (Lepidoptera: Noctuidae) under laboratory conditions. International Journal of Entomology 42(3-4): 413-416.

Giorni, P (2007) Impact on Environmental and Plant actors on Aspergillus section Flavi isolated from maize in Italy, Ph.D. Thesis. Faculty of Medicine and Biosciences, Cranfield Univesity, Italy.

Gupta RC (2012) Verterinary Toxicology. Basic and clinical Principles, $2^{\text {nd }}$ Edition. Elsevier, Inc. USA, pp. $1181-1190$.

IARC (International Agency for Research on Cancer) (2002) Traditional herbal medicines, some mycotoxins, napthalene, and styrene. Monographs on the evaluation of carcinogenic risks to humans 82: 171.

Karthikeyan M, Karthikeyan A, Velazhahan R, Madhavan S \& Jayaraj T (2013) Occurrence of aflatoxin in maize kernels and molecular characterisation of the producing organism, Aspergillus. African Journal of Biotechnology 12: 583-5840.

Lawley R, Curtis L \& Davis J (2012) The foods Safety hazard guide book. Royal Society of Chemistry, USA, pp. 207-211.

Ogah ED \& Ogbodo EN (2012) Assessing the Impact of Biodiversity Conservation in the Management of Maize Stalk Borer (Busseola fusca, F.) in Nigeria. Current Trends in Technology and Science 2(2): 234-238.

Plessis J (2003) Maize production. ARC-Grain Crops Institute, South Africa, pp. 1-9.

Saito M \& Machida S (1999) A rapid identification method for aflatoxin producing strains of Aspergillus flavus and $A$ parasiticus by ammonia vapour. Mycoscience 40: 205-208.

Samapundo S (2006) Post-harvest strategies for the prevention of fungal growth and mycotoxin production in corn, Ph.D. Thesis. University of Ghent, Belgium.

Sithole ZS (1989) Towards insect resistance maize for the third world proceedings- Symposium on methodologies for developing host plant resistance to maize insects. International maize and wheat improvement centre, pp. 286-288.

Watanabe T (2002) Pictorial Atlas of soil and seed fungi-Morphologies of cultured fungi and key to species, $2^{\text {nd }}$ Edition. CRC Press, USA. 